\title{
In Memory of Vladislav Aleksandrovich Lantsov (1938-2008)
}

\section{DOI: $10.1134 / \mathrm{S} 1022795408110197$}

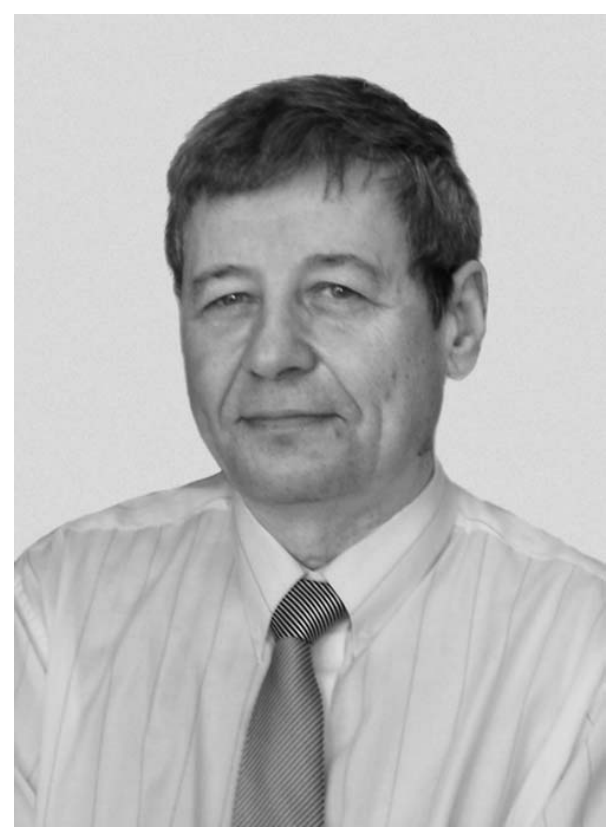

Professor Vladislav Aleksandrovich Lantsov, Dr. Sci. (Biol.), an outstanding researcher in the molecular genetics of bacteria and molecular biophysics renowned in Russia and worldwide, passed away on June 20, 2008.

Lantsov's series of studies on donor chromosome mobilization, transposons, recombination and hyperrecombination are widely known. In recent years, Lantsov comprehensively studied recA protein, including variation of its recombinant activities in various organisms and its interaction with DNA. Lantsov's latest studies dealt with molecular genetic diagnosis of malignant tumors and viral infections. His achievements in these fields were awarded with Honorable Science Prize of the Government of Leningrad oblast.

More than 20 years ago, Lantsov founded the Laboratory of Molecular Genetics of the Department of Radiation Biophysics of the St. Petersburg Institute of Nuclear Physics of the Russian academy of Sciences, which he headed until the last years of his life. Lantsov's numerous followers and students are working in many research institutions in Russia and abroad. Lantsov played the major role in founding, in collaboration with St. Petersburg Polytechnic University, Biophysics Research and Education Center. A year ago, Lantsov headed the Department of Biophysics of St. Petersburg State University and just began its reorganization.

Throughout his entire life, Lantsov remained faithful to the memory of his teacher S.E. Bresler.

Conferences dedicated to the memory of Bresler, which Lantsov organized in 2001 and 2006, and publication of their proceedings were notable events in science.

Lantsov's contributions to science and education are tremendous, and his plans destined to be unfulfilled were even more interesting and promising. The death of Lantsov, a person of great personal charm and remarkable commitment to work is a heavy bereavement for the scientific communities of St. Petersburg and Russia. We wish to express our condolence to Lantsov's relatives, friends, colleagues, and disciples. 